\title{
Study of gas-phase reactions within the modified Marcus model. IV. Arrhenius equation for the reaction $\mathrm{CH} 4+\mathrm{CH} 3$-> $\mathrm{CH} 3+\mathrm{CH} 4$
}

Igor Romanskii ( $\sim$ Ceng吕@yandex.ru)

Institut himiceskoj fiziki imeni N N Semenova RAN https://orcid.org/0000-0002-4957-5281

\section{Research Article}

Keywords: methane, methyl radical, hydrogen atom transfer, non-equilibrium model, Arrhenius equation

Posted Date: February 21st, 2022

DOI: https://doi.org/10.21203/rs.3.rs-1342824/v1

License: (c) (i) This work is licensed under a Creative Commons Attribution 4.0 International License. Read Full License 


\section{Abstract}

The results of a theoretical study (energy calculation level UCCSD $(T) / 6-31+G * * / / B 3 L Y P / 6-31+G * *$ ) of methane with methyl radical gas-phase reaction kinetics (Comp. Theor. Chem. 1125 (2018), Comp. Theor. Chem.1179 (2020) 112767) were used to analyze the Arrhenius equation in the temperatures range $2000-10 \mathrm{~K}$. A discussion within the framework of the previously proposed (Russ. Bull. Int. Ed. 2008, 57, 1842-1849) model, which is a modification of the non-equilibrium Marcus model, is based on direct ab initio calculations of the structure and energy of the varied activated reaction complex in a wide range of distances between the reactants. The Arrhenius equation is analyzed in terms of the change with temperature parameters in the reaction rate constant equation. The results obtained make it possible to distinguish three temperature ranges $(2000-900,900-100$ and $100-10 \mathrm{~K})$, which are qualitatively different from each other in the nature and degree of influence of various variable factors on the Arrhenius plot.

\section{Introduction}

This article continues the study of hydrogen atom transfer reaction between methane and methyl radical (Eq. (1)) from the standpoint of a non-equilibrium approach (Marcus 1957; Marcus 1968; Levich 1970; German 1980). Earlier (Romanskii 2018; Romanskii 2020; Romanskii 2020a) it was shown that the model, along with the description of the temperature dependence of the rate constant, makes it possible to track with temperature of individual terms in the kinetic equation. The purpose of this work is to analyze on this basis the Arrhenius equation for reaction (1) in the temperature range 2000 - $10 \mathrm{~K}$.

$\mathrm{CH}_{4}+\mathrm{CH}_{3} \rightarrow \mathrm{CH}_{3}+\mathrm{CH}_{4}(1)$

\section{Theoretical Model}

The theoretical models of the proton and hydrogen atom reaction in solution approach (Marcus 1957; Marcus 1968; Levich 1970; German 1980) are based on the generalized Frank-Condon principle (GFCP) (Kuznetsov 1986), according to which during the proton tunneling the heavy atoms of the system retain their positions. Adequate GFCP (somewhat simplified) scheme of the hydrogen atom (hereinafter $\mathrm{H}$-atom) transfer reaction includes the following stages:

(1) approach of the reactants to a certain distance $\mathrm{Q}$ between the $\mathrm{H}$-atom donor and acceptor atoms;

(2) non-equilibrium ( $\mathrm{H}$-atom in the initial state) reorganization of the system: movement of the system along the structural coordinate $\mathrm{q}$ at a fixed distance Q;

(3) tunneling of hydrogen: the movement of $\mathrm{H}$-atom along its coordinate $\mathrm{r}$ at fixed parameters $\mathrm{Q}$ and q;

(4) relaxation of reaction products and their separation.

For a fixed distance $\mathrm{Q}$, the potential of the system along the $\mathrm{H}$-atom coordinate $\mathrm{r}, \mathrm{V}(\mathrm{r} \mid \mathrm{Q})$, is double-well. The stage of reorganization consists in the potential $\mathrm{V}(\mathrm{r} \mid \mathrm{Q})$ symmetrization. The symmetrization requirement follows from the energy conservation law in the form of the need to equalize the vibrational levels of the $\mathrm{H}$-atom in the potential left and right wells.

Earlier (Romanskii 2008) the possibility of replacing the multidimensional structural coordinate q with a one-dimensional one was considered. As such, it is proposed to use the $\mathrm{H}$-atom coordinate $r$ in the limit when the motion along $r$ occurs in equilibrium. Movement along this equilibrium coordinate (denoted by the symbol $\rho$ ) at a fixed distance Q, as well as similar motion along the q coordinate, is accompanied by a rearrangement of the reaction system. There is a one-to-one correspondence between the energies $\mathrm{V}(\rho \mid \mathrm{Q})$ and $\mathrm{V}(\mathrm{q} \mid \mathrm{Q})$. The same correspondence exists between the coordinates $\rho$ and $\mathrm{q}$ : any point on the coordinate $\rho$ can be associated with a specific point on the coordinate $q$, and vice versa. This, in fact, determines the possibility of replacing the multidimensional coordinate $q$ with the one-dimensional coordinate $\rho$. The immediate advantage of such a replacement is the possibility of determining the geometry of the activated complex (AC) of 
the PT reaction using the procedure of partial (at fixed values of the parameters $Q$ and $\rho$ ) geometry optimization; this procedure is standard in software packages such as the Gaussian program. As a result, it becomes possible for ab initio calculation of the geometry (and energy) of a non-equilibrium AC in general case of asymmetric reaction.

Within this model, the thermal rate constant, $k(T)$, is calculated using the equation:

$k(T)=\sigma \int v_{t}(Q, T) \exp \left[-\Delta G^{*}(Q) / R T\right] d Q(2 a)$

$\Delta G *(Q)=\Delta H^{*}(Q)-T \Delta S^{*}(Q)(2 b)$

$\Delta H^{*}(Q)=E_{a}(Q)+\Delta h *(Q)(2 c)$

$\Delta S^{\star}(\mathrm{Q})=1000\left\{\left[\Delta \mathrm{h}^{\star}(\mathrm{Q})-\Delta \mathrm{g}^{\star}(\mathrm{Q})\right] / \mathrm{T}\right\}(2 \mathrm{~d})$

$\Delta h^{\star}(Q)=h *(Q)-h ; \Delta g^{\star}(Q)=g^{\star}(Q)-g(2 e)$

where $\sigma$ is the symmetry number (for Reaction (1) $\sigma=4$ ); $v_{t}$ is the tunneling frequency in the symmetric potential $V\left(r \mid Q, \rho^{\star}\right.$ ) ( $\rho^{\star}$ - $\rho$ coordinate for $A C$ ) $, \Delta G^{*}, \Delta H^{*}$ and $\Delta S^{*}$ are the free energy, enthalpy and entropy of activation, respectively, $E_{a}$ is the electronic activation energy of the reaction, $\Delta \mathrm{h}^{\star}$ and $\Delta \mathrm{g}^{\star}$ are the thermal corrections to the enthalpy and the free activation energy, respectively, where $h *(h)$ and $g^{\star}(g)$ are the corresponding thermal corrections for the AC (reagents); $R$ is the gas constant. The calculation of thermodynamic parameters is performed in the rigid rotor approximation without accounting for free and internal rotations of the AC and reactants.

The energy $E_{a}$ is defined as the sum of the equilibrium, $E_{a}{ }^{e q}$, and non-equilibrium, $E_{a}{ }^{\text {neq, }}$, components:

$E_{a}=E_{a}{ }^{e q}+E_{a}{ }^{\text {neq }}(3)$

To calculate the tunneling frequency $v_{t}(Q, T)$ the relation is used:

$v_{t}(Q, T)=v_{t}^{00}(Q)+\Sigma_{i} v_{t}^{i}(Q, T)(4 a)$

$\mathrm{v}_{\mathrm{t}}^{\mathrm{i}}(\mathrm{Q}, \mathrm{T})=\mathrm{v}_{\mathrm{t}}^{\mathrm{ii}}(\mathrm{Q}) \exp \left(\Delta \mathrm{V}_{\mathrm{i} 0}(\mathrm{Q}) / \mathrm{RT}\right)(4 \mathrm{~b})$

where $v_{t}{ }^{00}$ and $v_{t}{ }^{i i}$ are the frequencies of $\mathrm{H}$-atom tunneling between zero levels and the i-th levels of the double-well potential $\mathrm{V}\left(\mathrm{r} \mid \rho^{*}, \mathrm{Q}\right)$, respectively, and $\Delta \mathrm{Vi}_{0}$ is the energy difference between the $\mathrm{i}$-th and zero levels of the potential. Frequencies are calculated in the WKB approximation by the Brickmann method (Brickmann 1976; Czczesniak 1985)

Due to the opposite changes with the distance $\mathrm{Q}$ of the frequency and exponential terms in Eq. $2 \mathrm{a}$, the integrand passes through a maximum at some distance $Q=Q_{m}$. It was found that the calculation according to the equation for $k(T)$ at the point $Q_{m}, k_{m}(T)$ (Eq. 5), leads to the results, which are very close to the results of the calculation with Eq. 2 (see below).

$\mathrm{k}_{\mathrm{m}}(\mathrm{T})=\sigma \mathrm{A}_{\mathrm{m}} \exp \left(-\Delta \mathrm{H}_{\mathrm{m}}{ }^{*} / \mathrm{RT}\right)$

$A_{m}=v_{t}{ }^{m} \exp \left(\Delta S_{m}{ }^{*} / R\right) ;(5 b)$

$\Delta H_{m}=E_{a}{ }^{m}+\Delta h_{m} *(5 c)$

According to Eq. 4 the frequency $v_{t}{ }^{m}$ is defined as a cumulative quantity:

$v_{t}^{m}=v_{t, m}^{0}+v_{t, m}^{i},(6 a)$ 
where

$\mathrm{v}_{\mathrm{t}, \mathrm{m}}{ }^{0}=\mathrm{v}_{\mathrm{t}}^{00}\left(\mathrm{Q}_{\mathrm{m}}\right)(6 \mathrm{~b})$

and

$v_{t, m}{ }^{i}=\Sigma_{i} v_{t}^{i}\left(Q_{m}, T\right) .(6 c)$

The description of the reaction rate constant $\mathrm{k}_{\mathrm{m}}$ as a function of temperature presented below is based on a detailed analysis of Eqs. 5 and 6.

\section{Results And Discussion}

\subsection{Rate constants.}

The results of calculating the values of the rate constants k (Eq. 2) and $\mathrm{k}_{\mathrm{m}}$ (Eq. 5) (the energy calculation level UCCSD(T)/631+G**//B3LYP/6-31+G**) (Romanskii 2018; Romanskii 2020; Romanskii 2020a) for temperatures 2000 - $10 \mathrm{~K}$ are summarized in Table 1. The difference in the values of $k$ and $k_{m}$ is small. In the range $2000-100 \mathrm{~K}$, the $\mathrm{k}_{\mathrm{m}} / \mathrm{k}$ ratio is $4-5$ and only at lower temperatures increases to 10-12. The proximity of $k$ and $k_{m}$ values is clearly demonstrated by the Arrhenius plots for 2000 - $150 \mathrm{~K}$ (Fig. 1) and 150 - $10 \mathrm{~K}$ (Fig. 2). In the range of 2000-150 K, the log k and log $\mathrm{k}_{\mathrm{m}}$ temperature dependences are described by the equations of the fourth degree (Eqs. 7 and 8), and in the range of 150-10, by linear equations (Eqs. 9 and 10$)\left(t=10^{3} / 2.303 R T\right)$ :

Table 1

Rate constants $\mathrm{k}, \mathrm{k}_{\mathrm{m}}, \mathrm{I} \cdot \mathrm{mol}^{-1} \cdot \mathrm{s}^{-1}$

\begin{tabular}{|llllll|}
\hline $\mathbf{T}, \mathbf{K}$ & $\mathbf{k}$ & $\mathbf{k}_{\mathrm{m}}$ & $\mathbf{T}, \mathbf{K}$ & $\mathbf{k}$ & $\mathbf{k}_{\mathbf{m}}$ \\
\hline 2000 & $2.87(8)$ & $6.37(8)$ & 298.15 & 0.0836 & 0.385 \\
\hline 1800 & $1.31(8)$ & $3.17(8)$ & 250 & $2.44(-3)$ & 0.0118 \\
\hline 1600 & $5.64(7)$ & $1.46(8)$ & 200 & $1.00(-5)$ & $4.82(-5)$ \\
\hline 1400 & $2.06(7)$ & $6.25(7)$ & 150 & $3.36(-9)$ & $1.75(-8)$ \\
\hline 1200 & $5.56(6)$ & $1.82(7)$ & 120 & $2.18(-12)$ & $1.12(-11)$ \\
\hline 1000 & $1.03(6)$ & $3.72(6)$ & 100 & $2.09(-15)$ & $1.08(-14)$ \\
\hline 900 & $3.66(5)$ & $1.39(6)$ & 80 & $7.48(-20)$ & $4.06(-19)$ \\
\hline 800 & $8.96(4)$ & $3.67(5)$ & 60 & $5.04(-27)$ & $3.27(-26)$ \\
\hline 700 & $1.93(4)$ & $8.00(4)$ & 40 & $9.92(-41)$ & $6.61(-40)$ \\
\hline 600 & $2.67(3)$ & $1.17(4)$ & 20 & $2.86(-81)$ & $2.32(-80)$ \\
\hline 500 & 254 & $1.13(3)$ & 15 & $3.65(-108)$ & $3.55(-107)$ \\
\hline 400 & 11.6 & 53.0 & 10 & $6.64(-162)$ & $7.94(-161)$ \\
\hline 350 & 1.68 & 7.68 & & & \\
\hline
\end{tabular}


$\log k=7.70 t^{4}-27.75 t^{3}+36.86 t^{2}-32.35 t+11.57(7)$

$\log k_{m}=6.07 t^{4}-22.06 t^{3}+29.97 t^{2}-28.92 t+11.64(8)$

$\log k=-7.47 t+1.470(9)$

$\log \mathrm{k}_{\mathrm{m}}=-7.45 \mathrm{t}+2.17(10)$

\subsection{Energy and frequency characteristics of the reaction. Position $Q_{m}$.}

Table 2 contains the calculation data for the parameters included in the expression for the rate constant $k_{m}$ (Eq. 5); here are also the values of the distances $Q_{m}$ and the values of the tunneling frequencies $v_{t, m}{ }^{0}, v_{t, m}{ }^{i}$ and $v_{t}{ }^{m}$ corresponding to this point (Eq. 6). As seen from the table, in the temperature range $2000-10 \mathrm{~K}$, none of the parameters Eqs. 5 and 6 remains constant. By the nature of the effect of temperature on the activation parameters, the latter can be divided into three groups: 
Table 2

Terms of Eqs. $5 a-5 c$, values of $v_{t, m}{ }^{0}$ and $v_{t, m}{ }^{i}$ (Eq. 6); $Q_{m}$

\begin{tabular}{|c|c|c|c|c|c|c|c|c|c|c|}
\hline $\mathrm{T}, \mathrm{K}$ & $t, 10^{3} K^{-1}$ & $Q_{m}, A$ & $v_{t, m}{ }^{0}, s^{-1}$ & $v_{t, m}{ }^{i}, s^{-1}$ & $v_{t}^{m}, s^{-1}$ & $-\Delta S^{*}{ }_{m}^{a)}$ & $A_{m}, s^{-1}$ & $E_{a}^{m b)}$ & $\Delta h^{*}{ }_{m}^{b)}$ & $\left.\Delta H_{m} * b\right)$ \\
\hline 2000 & 0.5 & 2.85 & $2.38(12)$ & $2.24(13)$ & $2.48(13)$ & 14.44 & $1.74(10)$ & 11.70 & 6.94 & 18.64 \\
\hline 1800 & 0.556 & 2.85 & $2.38(12)$ & $1.86(13)$ & $2.10(13)$ & 14.73 & $1.27(10)$ & 11.70 & 6.44 & 18.14 \\
\hline 1600 & 0.625 & 2.85 & $2.38(12)$ & $1.53(13)$ & $1.77(13)$ & 15.39 & 7.67(9) & 11.70 & 5.30 & 16.99 \\
\hline 1400 & 0.714 & 2.825 & $4.02(12)$ & $1.56(13)$ & $1.96(13)$ & 15.99 & $6.26(9)$ & 12.19 & 4.47 & 16.66 \\
\hline 1200 & 0.833 & 2.825 & $4.02(12)$ & $1.10(13)$ & $1.50(13)$ & 16.60 & $3.54(9)$ & 12.19 & 3.67 & 15.86 \\
\hline 1000 & 1 & 2.825 & $4.02(12)$ & $7.68(12)$ & $1.17(13)$ & 17.32 & $1.92(9)$ & 12.19 & 2.87 & 15.06 \\
\hline 900 & 1.11 & 2.80 & $6.47(12)$ & $7.03(12)$ & $1.35(13)$ & 17.88 & $1.66(9)$ & 12.71 & 2.44 & 15.15 \\
\hline 800 & 1.25 & 2.80 & $6.47(12)$ & $4.33(12)$ & $1.08(13)$ & 18.49 & $9.84(8)$ & 12.71 & 2.03 & 14.74 \\
\hline 700 & 1.429 & 2.825 & $4.02(12)$ & $2.63(12)$ & $6.65(12)$ & 19.08 & $4.51(8)$ & 12.19 & 1.74 & 13.93 \\
\hline 600 & 1.667 & 2.825 & $4.02(12)$ & $1.54(12)$ & $5.56(12)$ & 19.80 & $2.62(8)$ & 12.19 & 1.40 & 13.59 \\
\hline 500 & 2 & 2.85 & $2.38(12)$ & $7.40(11)$ & $3.12(12)$ & 20.28 & $1.15(8)$ & 11.70 & 1.13 & 12.83 \\
\hline 400 & 2.5 & 2.85 & $2.38(12)$ & $2.60(11)$ & $2.64(12)$ & 20.29 & $9.71(7)$ & 11.70 & 0.86 & 12.56 \\
\hline 350 & 2.857 & 2.90 & $7.83(11)$ & $3.52(10)$ & $7.83(11)$ & 21.79 & $2.47(7)$ & 10.81 & 0.81 & 11.62 \\
\hline 298.15 & 3.354 & 2.90 & $7.83(11)$ & & $7.83(11)$ & 20.46 & $2.65(7)$ & 10.81 & 0.70 & 11.51 \\
\hline 250 & 4 & 2.95 & $1.96(11)$ & & $1.96(11)$ & 20.57 & $6.26(6)$ & 10.01 & 0.66 & 10.67 \\
\hline 200 & 5 & 3.0 & $3.21(10)$ & & $3.21(10)$ & 20.80 & $9.10(5)$ & 9.34 & 0.61 & 9.95 \\
\hline 150 & 6.667 & 3.05 & $6.69(9)$ & & $6.69(9)$ & 21.00 & $1.72(5)$ & 8.75 & 0.58 & 9.33 \\
\hline 120 & 8.333 & 3.125 & $4.41(8)$ & & $4.41(8)$ & 20.81 & $1.25(4)$ & 8.02 & 0.57 & 8.59 \\
\hline 100 & 10 & 3.15 & $1.80(8)$ & & $1.80(8)$ & 20.44 & $6.12(3)$ & 7.82 & 0.58 & 8.40 \\
\hline 80 & 12.5 & 3.225 & $1.03(7)$ & & $1.03(7)$ & 19.99 & 441 & 7.32 & 0.59 & 7.92 \\
\hline 60 & 16.67 & 3.275 & $1.44(6)$ & & $1.44(6)$ & 18.74 & 116 & 7.06 & 0.66 & 7.73 \\
\hline 40 & 25 & 3.35 & $5.91(4)$ & & $5.91(4)$ & 16.38 & 15.56 & 6.79 & 0.71 & 7.50 \\
\hline 20 & 50 & 3.45 & 640 & & 640 & 11.31 & 2.16 & 6.66 & 0.77 & 7.37 \\
\hline 15 & 66.7 & 3.5 & 87.1 & & 87.1 & 9.00 & 0.939 & 6.57 & 0.77 & 7.34 \\
\hline 10 & 100 & 3.5 & 87.1 & & 87.1 & 5.70 & 4.93 & 6.568 & 0.815 & 7.383 \\
\hline
\end{tabular}

(1) parameters for which the effect of temperature manifests itself directly: $\Delta S_{m}{ }^{*}, \Delta h_{m}{ }^{*}$ and $v_{t, m}$ i;

(2) the effect of temperature is associated with changes in the quantities $Q_{m}: v_{t, m}{ }^{0}$ and $E_{a} m$;

(3) both factors act: $v_{t}^{m}$ 
The first of these effects manifests itself in the region of relatively high temperatures, starting from $2000 \mathrm{~K}$ and up to $350 \mathrm{~K}$. In this temperature range, changes in the entropy term $\Delta S_{m}$ * (from - 14.7 to -21.7 e.u.) and the enthalpy term $\Delta \mathrm{h}_{\mathrm{m}}$ * ( from 6.9 to $0.8 \mathrm{kcal} \mathrm{mol}^{-1}$ partially compensate each other. At lower temperatures, the value of $\Delta \mathrm{S}_{\mathrm{m}}{ }^{*}$ gradually increases to approx. -16 e.u. at $40 \mathrm{~K}$ and approx. -6 e.u. at $10 \mathrm{~K}$. In the same region temperature, the value of $\Delta \mathrm{h}_{\mathrm{m}}$ * changes only slightly: after a decrease to $0.6 \mathrm{kcal} \mathrm{mol}^{-1}$ at $120 \mathrm{~K}$, it again increases to $0.8 \mathrm{kcal} \mathrm{mol}^{-1}$ at $10 \mathrm{~K}$.

At $2000 \mathrm{~K}$, excited vibrational levels play the main role in the transfer of a hydrogen atom: the frequency $\mathrm{v}_{\mathrm{t}, \mathrm{m}}{ }^{\mathrm{i}}$ is $\sim 90 \%$ of the total frequency $\mathrm{v}_{\mathrm{t}}{ }^{\mathrm{m}}$; with decreasing temperature, the contribution of $\mathrm{v}_{\mathrm{t}, \mathrm{m}}{ }^{\mathrm{i}}$ gradually decreases to zero at $350 \mathrm{~K}$. Starting from this temperature, the transfer rate of the $\mathrm{H}$-atom is entirely determined by the frequency of tunneling from the ground level.

The participation of excited levels in the reaction leads to a broadening of the maximum on the Q $-v_{t}{ }^{m}$ plot (Fig. 5 in (Romanskii 2020)) and, as a consequence, to a slight increase in $Q_{m}$ - up to $2.85 \mathrm{~A}$ at 2000 - $1600 \mathrm{~K}$. A decrease in the population of excited levels in the range $1600-800 \mathrm{~K}$ is accompanied by a decrease in $Q_{m}$ to $2.80 \mathrm{~A}$. A further decrease in temperature and the associated increase in the role of the fundamental oscillatory level lead to a new increase in $Q_{m}(s e e$ below).

Overall, in the temperature range 2000 - $400 \mathrm{~K}$, the value of $Q_{m}$ changes only slightly, varying within $2.80-2.85 \mathrm{~A}$. At these values of $Q$, the height of the barrier in the double-well potential $V\left(r \mid Q, \rho^{*}\right), E_{b}$, is $6.9-8.9 \mathrm{kcal} \mathrm{mol}^{-1}$ (Table 3). The relatively small height of the barrier creates a situation in which all oscillatory levels, except for the zero one, are above the barrier (Table 3). Accordingly, the ratio of the frequencies of the over-barrier and sub-barrier transitions of the hydrogen atom, $n$, can be determined from the relation

Table 3

The height of the barrier $E_{b}$, the energy of the zero, $E_{0}{ }^{a}$, and the first, $\mathrm{E}_{1}{ }^{\mathrm{a})}$, vibrational levels, $\mathrm{kcal} \mathrm{mol}{ }^{-1}$

\begin{tabular}{|llllllll|}
\hline Q, A & $\mathrm{E}_{\mathrm{b}}$ & $\mathrm{E}_{0}$ & $\mathrm{E}_{1}$ & $\mathrm{Q}, \mathrm{A}$ & $\mathrm{E}_{\mathrm{b}}$ & $\mathrm{E}_{0}$ & $\mathrm{E}_{1}$ \\
\hline 2.7 & 3.44 & -0.99 & 4.52 & 2.95 & 13.27 & -8.91 & -1.83 \\
\hline 2.75 & 5.07 & -1.55 & 3.38 & 3.0 & 15.57 & -11.09 & -3.38 \\
\hline 2.8 & 6.90 & -3.35 & 1.85 & 3.1 & 20.40 & -15.79 & -7.33 \\
\hline 2.825 & 7.88 & -4.15 & 1.26 & 3.2 & 25.36 & -20.70 & -11.95 \\
\hline 2.85 & 8.89 & -4.96 & 0.67 & 3.3 & 30.33 & -25.68 & -16.62 \\
\hline 2.875 & 9.93 & -5.89 & 0.03 & 3.4 & 35.29 & -30.68 & -21.82 \\
\hline 2.9 & 11.01 & -6.83 & -0.52 & 3.5 & 40.02 & -35.48 & -26.69 \\
\hline a) The top of the barrier is taken as the origin. & & \\
\hline
\end{tabular}

$\mathrm{n}=\mathrm{v}_{\mathrm{t}, \mathrm{m}}{ }^{\mathrm{i}} / \mathrm{v}_{\mathrm{t}, \mathrm{m}}{ }^{0}(11)$ 
In the temperature range 2000 - $350 \mathrm{~K}$, the value of $\mathrm{n}$ changes from 9.4 to zero (Fig. 3). In the instanton literature, the value $\mathrm{n}=1$ corresponding to the equalization of the rates of over- and

sub-barrier transitions is defined by the term "crossover temperature" (Hanggi 1990). In this case, as seen from the figure, the crossover temperature is $\sim 900 \mathrm{~K}$.

The relationship between the quantities $v_{t, m}{ }^{0}$ and $E_{a}{ }^{m}$ with $Q_{m}$ is due to the direct dependence of the frequency $v_{t}{ }^{0}$ and energy $E_{a}$ on $Q$ : with increasing $Q$, both quantities decrease. Since the rate constant is proportional to $v_{t}{ }^{0}$ and inversely proportional to $E_{a}, k \sim v_{t}{ }^{0} \exp \left(-E_{a} / R T\right)$, the frequency factor shifts $Q_{m}$ towards smaller values, and the energy factor shifts towards large $\mathrm{Q}$. With decreasing temperature, the role of the energy factor (due to the factor $\mathrm{t} \sim \mathrm{T}^{-1}$ ) increases; leading to a gradual increase in $Q_{m}$.

Small variations in $Q_{m}$ in the temperature range 2000 - $400 \mathrm{~K}$ correspond to small variations (within $\sim 1 \mathrm{kcal} \mathrm{mol}^{-1}$ ) in the energy $E_{a}{ }^{m}$. In the most obvious form, the correlation between the values of $Q_{m}$ and $E_{a}{ }^{m}$ is observed in the temperature range from 400 to $\sim 120 \mathrm{~K}$. Beginning at $120 \mathrm{~K}$, the decrease in $\mathrm{E}_{\mathrm{a}}{ }^{\mathrm{m}}$ becomes less noticeable. The reason for this is the shape of the $E_{a}(Q)$ curve, characterized by the presence of a minimum at $Q=3.50$ A (Fig. 2 in (Romanskii 2018)). At low temperatures, even a slight increase in the energy of the system in the region $\mathrm{Q}>3.50 \mathrm{~A}$ sharply decreases the reaction rate; as a result, the value $Q_{m}=3.50 \mathrm{~A}$, attained at $15 \mathrm{~K}$, turns out to be the limiting one.

Let us now see to what extent the temperature changes in the frequency and energy characteristics of the reaction described above affect the form of the Arrhenius equation.

\subsection{Analysis of the Arrhenius equation.}

For what follows, we write down the equations for the rate constant $k_{m}$ (Eq. 5) in the logarithmic form:

$\log k_{m}=\log \sigma+\log A_{m}-\left(\Delta H_{m}{ }^{*}\right) / 2.3 R T(12 a)$

$\log A_{m}=\log v_{t}^{m}+\Delta S_{m} * / 2.3 R(12 b)$

$-\Delta H_{m}{ }^{*} / 2.3 R T=-E_{a}{ }^{m} / 2.3 R T-\Delta h_{m}{ }^{*} / 2.3 R T(12 c)$

The general view of the term dependences in Eq. 12b on temperature in the intervals $2000-150$ and $150-10 \mathrm{~K}$ are shown in Figs. 4 and 5, respectively. Similar dependences for the terms of Eqs. 12c and 12a are shown in Figs. 6, 7 and 8, 9, respectively. Curve equations in Figs. $4-7$ are given in Table 4 . 
The equations of the curves in Fig. $4-7\left(t=10^{3} / 2.303 R T\right)$

\begin{tabular}{|c|c|c|c|}
\hline Figure $^{a)}$ & Curve & $2000-150 K$ & $150-10 K$ \\
\hline \multirow[t]{3}{*}{4,5} & 1 & $\log v_{t}^{m}=1.06 t^{3}-2.45 t^{2}-1.217 t+13.50$ & $\log v_{t}^{m}=-2.76 .10^{-3} t^{3}+0.128 t^{2}-1.94 t+11.89$ \\
\hline & 2 & $\begin{array}{l}\Delta S_{m} * / 2.3 R=-3.27 t^{3}+9.20 t^{2}-7.95 t- \\
2.44\end{array}$ & $\begin{array}{l}\Delta \mathrm{S}_{\mathrm{m}}{ }^{\star} / 2.3 \mathrm{R}=-4.92 .10^{-4} \mathrm{t}^{3}+0.0127 \mathrm{t}^{2}+0.118 \mathrm{t} \\
-4.78\end{array}$ \\
\hline & 3 & $\log A_{m}=-2.21 t^{3}+6.75 t^{2}-9.17 t+11.05$ & $\log A_{m}=-3.2510^{-3} t^{3}+0.141 t^{2}-1.83 t+7.10$ \\
\hline \multirow[t]{3}{*}{6,7} & 1 & $\begin{array}{l}E_{a}^{m} / 2.3 R T=-2.76 t^{3}+9.03 t^{2}-16.34 t+ \\
0.44\end{array}$ & $\mathrm{E}_{\mathrm{a}}^{\mathrm{m}} / 2.3 \mathrm{RT}=-6.42 \mathrm{t}-2.69$ \\
\hline & 2 & $\Delta{ }^{\star}{ }_{m} / 2.3 R T=8.00 t^{3}-2.48 t^{2}+2.00 t-0.95$ & $\Delta \mathrm{h}_{\mathrm{m}}^{*} / 2.3 \mathrm{RT}=-0.831 \mathrm{t}-0.568$ \\
\hline & 3 & $\begin{array}{l}\Delta H_{m}{ }^{*} / 2.3 R T=-1.96 t^{3}+6.54 t^{2}-14.34 t- \\
0.51\end{array}$ & $\Delta \mathrm{H}_{\mathrm{m}} * / 2.3 \mathrm{RT}=-7.25 \mathrm{t}-2.12$ \\
\hline
\end{tabular}

For a more detailed analysis of Eq. 12, we calculated the slope (coefficient a in the linear equation (Eq. 13) and curvature $\eta$ (doubled value of the coefficient at the first term of the quadratic equation (Eq. 14) for limited sections of the corresponding temperature curves. In the first case, the entire temperature range from 2000 to $10 \mathrm{~K}$ was divided into eight sections, each of which contained data for four temperatures. In the second case, four intervals were used with data for eight temperatures.

$y_{1}=a t+b ;(13)$

$y_{2}=a t^{2}+b t+c ;(14 a)$

$\eta=2 a .(14 b)$

The found values of a and $\eta$ are considered below for each of Eqs. (12a) - (12c) separately. A full description of the design parameters for Eqs. (13) and (14) is given in Supplementary Materials (Tables 1S - 6S).

\subsection{1. $\log A_{m}=\log v_{t}^{m}+\Delta S_{m} * / 2.3 R(E q .(12 b))$}

Slope. For the plot $\mathrm{t}-\log \mathrm{A}_{\mathrm{m}}$ (Figs. 4 and 5), value a in the range from 2000 to $10 \mathrm{~K}$ changes monotonically from -2.1 to zero (Table 5). At high temperatures $(2000-900 \mathrm{~K})$, the main contribution to the negative slope of the $\mathrm{t}-\log \mathrm{A}_{\mathrm{m}}$ plot is made by the change in the term $\Delta S_{m}{ }^{*} / 2.3 R$. The relatively small (negative) slope for the $t-\log v_{t}{ }^{m}$ plot is due to opposite sign changes for $\log v_{t, m}{ }^{i}$ and $\lg v_{t, m}{ }^{0}$. With decreasing temperature $(900-40 \mathrm{~K})$, the role of the $\log v_{t}{ }^{m}$ term becomes dominant, and in the temperature range of $40-10 \mathrm{~K}$, the two components almost completely compensate each other.

Curvature. The high positive $(\eta=2.86)$ curvature of the $t-\log A_{m}$ plot observed in the temperature range $2000-900 \mathrm{~K}$ is made up of two approximately identical contributions of the frequency and entropic terms. The curvature of the $t-\log v_{t}{ }^{m}$ plot is almost entirely related to changes in the $\log v_{t, m}{ }^{i}$ value. In the range $900-100 \mathrm{~K}$, the curvature of the $t$ - $\log A_{m}$ plot decreases sharply, and its positive value is alternately provided by positive values of $\eta$ for the entropy (900 - $350 \mathrm{~K})$ and frequency $(350-100 \mathrm{~K})$ terms. In the range of $100-10 \mathrm{~K}$, all three plots are linear $(\eta=0)$. 


\subsection{2. $-\Delta H_{m} * / 2.3 R T=-E_{a} m / 2.3 R T-\Delta h_{m} * / 2.3 R T(E q .(12 c))$}

Slope. For the plot of t - $-\Delta \mathrm{H}_{\mathrm{m}}$ */2.3RT (Fig. 6 and 7), the a value varies from -2.6 (2000 - $\left.1400 \mathrm{~K}\right)$ to -1.6 (40 - $\left.10 \mathrm{~K}\right)$ (Table 5). The main influence on the slope of this plot is exerted by the change in the term $-E_{a} m / 2.3 R T$. Variation with temperature of the term $-\Delta h_{m} * / 2.3 R T$ is characterized by a change in the sign of the slope - from positive at higher ones to negative at lower ones. Positive values of at high temperatures reflect a rapid decrease in energy $\Delta \mathrm{h}_{\mathrm{m}}{ }^{*}$ - faster than an increase in this region at the reciprocal temperature $t$.

Curvature. The curvature of the $\mathrm{t}--\Delta \mathrm{H}_{\mathrm{m}}{ }^{*} / 2.3 \mathrm{R} T$ plot, like its slope, is mainly determined by changes in the $-\mathrm{E}_{\mathrm{a}} \mathrm{m} / 2.3 \mathrm{RT}$ term. In both cases, a change in the sign of the curvature is observed - from negative (2000 - $900 \mathrm{~K})$ to positive (900 - $350 \mathrm{~K})$.

\subsection{3. $\log k_{m}=\log \sigma+\log A_{m}-\Delta H_{m} * / 2.3 R T($ Eq. (12a))}

Slope. In accordance with the data of the two previous sections, the slope of the $t$ - $\log k_{m}$ plot (Figs. 8 and 9) varies from $-4.7(2000-1400)$ to $-1.6(40-10 \mathrm{~K})$ (Table 6). As already noted (see Section 3.2.1), with decreasing temperature, the slope of the $\mathrm{t}-\log \mathrm{A}_{\mathrm{m}}$ plot at $40-10 \mathrm{~K}$ decreases to zero. At the same time, in a very wide temperature range (from 2000 to $100 \mathrm{~K}$ ), the share of this contribution in the "observed" value of the slope of the $t$ - log $k_{m}$ plot remains significant, ranging from $\sim 45 \%(2000-1400 \mathrm{~K})$ to $24 \%(200-100 \mathrm{~K})$.

Table 5. The values of the slope a (Eq. 13) and curvature $\eta$ (Eq. 14) for the terms of the equation $\log A_{m}=\log v_{t}^{m}+\Delta S_{m} * / 2 \cdot 3 R($ Eq. 12b)

\begin{tabular}{|c|c|c|c|c|c|c|c|c|c|c|c|}
\hline \multirow{2}{*}{$\begin{array}{l}\text { Interval } \\
. \mathrm{T}, \mathrm{K}\end{array}$} & \multicolumn{5}{|c|}{ a } & \multirow{2}{*}{$\begin{array}{l}\text { Interval } \\
. \mathrm{T}, \mathrm{K}\end{array}$} & \multicolumn{5}{|c|}{$\eta$} \\
\hline & $\lg _{t, m} 0$ & $\lg v_{t, m}^{i}$ & $\lg v_{t} m$ & $\Delta \mathrm{S}_{\mathrm{m}}{ }^{*} / 2.3 \mathrm{R}$ & $\lg A_{m}$ & & $\lg _{t, m} 0$ & $\lg v_{t, m}{ }^{i}$ & $\lg v_{t}^{m}$ & $\Delta \mathrm{S}_{\mathrm{m}}{ }^{*} / 2.3 \mathrm{R}$ & $\lg A_{m}$ \\
\hline $\begin{array}{l}2000- \\
1400\end{array}$ & 1.02 & -1.51 & -0.49 & -1.63 & -2.12 & \multirow[t]{2}{*}{$\begin{array}{l}2000 \\
-900\end{array}$} & \multirow[t]{2}{*}{-0.15} & \multirow[t]{2}{*}{1.41} & \multirow[t]{2}{*}{1.26} & \multirow[t]{2}{*}{1.60} & \multirow[t]{2}{*}{2.86} \\
\hline $\begin{array}{l}1400- \\
900\end{array}$ & 0.44 & -0.89 & -0.45 & -1.03 & -1.48 & & & & & & \\
\hline $\begin{array}{l}900- \\
600\end{array}$ & -0.44 & -0.28 & -0.72 & -0.75 & -1.47 & \multirow[t]{2}{*}{$\begin{array}{l}900- \\
350\end{array}$} & \multirow[t]{2}{*}{-0.24} & \multirow[t]{2}{*}{0.16} & \multirow[t]{2}{*}{-0.08} & \multirow[t]{2}{*}{0.219} & \multirow[t]{2}{*}{0.134} \\
\hline $\begin{array}{l}600- \\
350\end{array}$ & -0.53 & -0.10 & -0.63 & -0.31 & -0.94 & & & & & & \\
\hline $\begin{array}{l}350- \\
200\end{array}$ & -0.68 & -0.01 & -0.69 & 0.07 & -0.62 & \multirow[t]{2}{*}{$\begin{array}{l}350- \\
100\end{array}$} & \multirow[t]{2}{*}{0.05} & \multirow[t]{2}{*}{0.00} & \multirow[t]{2}{*}{0.05} & \multirow[t]{2}{*}{-0.003} & \multirow[t]{2}{*}{0.049} \\
\hline $\begin{array}{l}200- \\
100\end{array}$ & -0.48 & 0.00 & -0.48 & 0.02 & -0.46 & & & & & & \\
\hline $100-40$ & -0.22 & 0.00 & -0.22 & 0.03 & -0.19 & \multirow{2}{*}{$\begin{array}{l}100- \\
10\end{array}$} & \multirow[t]{2}{*}{0.00} & \multirow[t]{2}{*}{0.00} & \multirow[t]{2}{*}{0.00} & \multirow[t]{2}{*}{0.002} & \multirow[t]{2}{*}{0.002} \\
\hline $40-10$ & -0.04 & 0.00 & -0.04 & 0.04 & 0.00 & & & & & & \\
\hline
\end{tabular}


Table 6. The values of the slope a (Eq. 13) and curvature $\eta$ (Eq. 14) for the terms of the equation: $-\Delta H_{m} * / 2.3 R T=-E_{a} m / 2.3 R T$ $+\left(-\Delta \mathrm{h}_{\mathrm{m}} * / 2.3 \mathrm{RT}\right)$ (Eq. 12c)

\begin{tabular}{|c|c|c|c|c|c|c|c|}
\hline \multirow{3}{*}{$\begin{array}{l}\text { Interval } \\
\mathrm{T}, \mathrm{K}\end{array}$} & \multicolumn{3}{|l|}{ a } & \multirow{3}{*}{$\begin{array}{l}\text { Interval } \\
. \mathrm{T}, \mathrm{K}\end{array}$} & \multicolumn{3}{|c|}{$\eta$} \\
\hline & $-\Delta h_{m} * /$ & $-E_{a}{ }^{m} /$ & $-\Delta \mathrm{H}_{\mathrm{m}}{ }^{\star} /$ & & $-\Delta \mathrm{h}_{\mathrm{m}}{ }^{*} /$ & $-E_{a}^{m} /$ & $-\Delta H_{m} * /$ \\
\hline & 2.3RT & 2.3RT & 2.3RT & & 2.3RT & 2.3RT & 2.3RT \\
\hline $2000-1400$ & 0.35 & -2.90 & -2.55 & $2000-900$ & -0.16 & -0.86 & -1.02 \\
\hline $1400-900$ & 0.26 & -2.93 & -2.67 & & & & \\
\hline $900-600$ & 0.13 & -2.38 & -2.25 & $900-350$ & -0.14 & 0.55 & 0.41 \\
\hline $600-350$ & 0.01 & -2.03 & -2.02 & & & & \\
\hline $350-200$ & -0.08 & -1.56 & -1.64 & $350-100$ & -0.01 & 0.05 & 0.04 \\
\hline $200-100$ & -0.12 & -1.35 & -1.47 & & & & \\
\hline $100-40$ & -0.18 & -1.34 & -1.52 & $100-10$ & 0.000 & -0.001 & -0.001 \\
\hline $40-10$ & -0.18 & -1.42 & -1.60 & & & & \\
\hline
\end{tabular}

Table 7 The values of the slope a (Eq. 13) and curvature $\eta$ (Eq. 14) for the terms of the equation $\log k_{m}=\log A_{m}$ - $\Delta \mathrm{H}_{\mathrm{m}}{ }^{*} / 2.3 \mathrm{RT}$ (Eq. 12a)

\begin{tabular}{|c|c|c|c|c|c|c|c|}
\hline \multirow{2}{*}{$\begin{array}{l}\text { Interval } \\
\mathrm{T}, \mathrm{K}\end{array}$} & \multicolumn{2}{|c|}{ a } & \multirow[b]{2}{*}{$\log k_{m}$} & \multirow{2}{*}{$\begin{array}{l}\text { Interval } \\
\mathrm{T}, \mathrm{K}\end{array}$} & \multicolumn{2}{|r|}{$\eta$} & \multirow[b]{2}{*}{$\log k_{m}$} \\
\hline & $\log A_{m}$ & $-\Delta \mathrm{H}_{\mathrm{m}}{ }^{*} / 2.3 \mathrm{RT}$ & & & $\log A_{m}$ & $-\Delta \mathrm{H}_{\mathrm{m}} * / 2.3 \mathrm{RT}$ & \\
\hline $2000-1400$ & -2.12 & -2.55 & -4.67 & $2000-900$ & 2.86 & -1.02 & 1.84 \\
\hline $1400-900$ & -1.47 & -2.67 & -4.14 & & & & \\
\hline $900-600$ & -1.47 & -2.25 & -3.72 & $900-350$ & 0.13 & 0.41 & 0.54 \\
\hline $600-350$ & -0.94 & -2.02 & -2.96 & & & & \\
\hline $350-200$ & -0.62 & -1.64 & -2.26 & $350-100$ & 0.049 & 0.048 & 0.097 \\
\hline $200-100$ & -0.46 & -1.47 & -1.93 & & & & \\
\hline $100-40$ & -0.19 & -1.52 & -1.71 & $100-10$ & 0.002 & -0.001 & 0.001 \\
\hline $40-10$ & -0.001 & -1.60 & -1.60 & & & & \\
\hline
\end{tabular}

Curvature. In the temperature range 2000 - $100 \mathrm{~K}$, the curvature of the $\mathrm{t}-\log \mathrm{k}$ plot is positive. With a decrease in temperature, the value of $\eta$ gradually decreases to zero (range $100-10 \mathrm{~K}$ ). As noted above (Section 3.2.2), in the 
temperature range $2000-900 \mathrm{~K}$, the plot $\mathrm{t}--\Delta \mathrm{H}_{\mathrm{m}}$ */2.3RT is characterized by a negative value of $\eta$; a positive value of $\eta$ for the resulting plot of $t-\log k$ is determined in this case by changes in $\log A_{m}$.

\section{General Conclusions}

The kinetics analysis of reaction (1) in the temperature range 2000 - $10 \mathrm{~K}$ makes it possible to distinguish three temperature ranges that differ in the nature and degree of influence of various factors on the form of the $\mathrm{t}$ - log $\mathrm{k}$ plot.

(1) 2000 - $900 \mathrm{~K}$. At high temperatures, excited vibrational levels play an important role. Their influence is manifested in (1) as a slight increase in $Q_{m}$ and (2) the predominance of the over-barrier mechanism of H-atom transfer. At $2000 \mathrm{~K}, Q_{m}=2.85$ $\mathrm{A}$, and the over-barrier transfer rate is $\sim 90 \%$ of the total transfer rate of the $\mathrm{H}$-atom in the double-well potential. At $900 \mathrm{~K}$, the value of $Q_{m}$ decreases to $2.80 \mathrm{~A}$, and the fraction of over-barrier transition is $\sim 50 \%$ ("crossover temperature"). A decrease in the population of excited levels leads to a decrease in the entropy $\left(\Delta \mathrm{S}_{\mathrm{m}}{ }^{*}\right)$ and enthalpy $\left(\Delta \mathrm{h}_{\mathrm{m}}{ }^{*}\right)$ components. The related kinetic effects are partially compensated for by an increase (due to the shift in $Q_{m}$ ) in the tunneling frequency $\left(v_{t, m}{ }^{0}\right)$ and the activation energy $E_{a}$. The form of the $t-\log k_{m}$ plot in this temperature range substantially depends on changes in $\log A_{m}$. The latter causes a large positive curvature of the plot, and their contribution to the slope is approximately $40 \%$.

(2) 900 - $100 \mathrm{~K}$. In this temperature range thermo-chemical parameters $\left(\Delta \mathrm{h}_{\mathrm{m}}{ }^{*}\right.$ and $\left.\Delta \mathrm{S}_{\mathrm{m}}{ }^{*}\right)$ change relatively weakly. The main influence on the form of the $t-\log k_{m}$ plot is exerted by the competition of frequency $\left(v_{t, m}{ }^{0}\right)$ and energy $\left(E_{a}{ }^{m}\right)$ factors. The observed increase in $Q_{m}$ (from $2.80 \mathrm{~A}$ at $900 \mathrm{~K}$ to $3.15 \mathrm{~A}$ at $100 \mathrm{~K}$ ) reflects the predominant role of the energy factor. The role of tunneling in this case turns out to be twofold. On the one hand, tunneling makes possible the transition of the $\mathrm{H}$ atom far from the saddle point. This leads to a decrease in the activation enthalpy $\Delta H_{m}{ }^{*}$ and a related decrease (in absolute value) in the negative slope of the $t-\log k_{m}$ plot. On the other hand, a decrease in the frequency $v_{t, m}{ }^{0}$ accompanied by an increase in $Q_{m}$ partially compensates for the first effect. The positive curvature of the $t$ - log $k_{m}$ plot is determined by both the changes in $\Delta \mathrm{H}_{\mathrm{m}}{ }^{*}$ and $\mathrm{v}_{\mathrm{t}, \mathrm{m}}{ }^{0}$. The rapid growth of the factor $\mathrm{t}$ with decreasing temperature leads to (1) an increase in "the weight" of the term $-\Delta H_{m}{ }^{*} / 2.3 R T$ in Eq. (13) and (2) a decrease in the curvature of the $t-\log k_{m}$ plot.

(3) 100 - $10 \mathrm{~K}$. The proximity to the "limiting" (Section 3.1) value of $Q_{m}$ causes a small $\left(\sim 1 \mathrm{kcal} \mathrm{mol}^{-1}\right)$ change in the energy $E_{a}{ }^{m}$ with a relatively large (3.5 orders of magnitude) change in the value of $\log A_{m}$. The competition between the frequency and energy factors leads to a shift in $Q_{m}$ from 3.15 to $3.5 \mathrm{~A}$. While the change in the value of $\log A_{m}$ is quite large, it practically does not affect the form of the Arrhenius dependence. The complete dominance of the energy component $-\Delta H_{m} * / 2.3 R T$ in this temperature range, as well as the linearity of the $t-\log k_{m}$ plot, is provided by very high values of $t$.

The discussion shows that the simple, "smooth" form of the $t-\log k_{m}$ plot hides a rather complex physical picture of the phenomenon. As the most characteristic features of this model, we note:

(1) Changes in the pre-exponent $A_{m}$ in the temperature range $2000-100 \mathrm{~K}$. At 2000-600 K, accompanying changes in the shape (slope and curvature) of the kinetic curve reflect mainly changes in the entropy of activation, and at 600-100 K - in the tunneling frequency.

(2) An increase in the $Q_{m}$ distance at 600-100 K as a result of competition between frequency and energy factors with an increasing predominance of the latter.

(3) Linearity at $100-10 \mathrm{~K}$ of the $\mathrm{t}-\log \mathrm{k}_{\mathrm{m}}$ plot, as a result of the dominance (with a slight change) of the enthalpy term.

\section{References}


Brickmann J (1976) Proton Motions in Hydrogen Bond. In: Schuster P, Zandel G, Sandorfy C (eds) The Hydrogen Bond - Recent Developments in Theory and Experiments, North-Holland Publishing Co., Amsterdam, pp 217-244.

German ED, Kuznetsov AM, Dogonadze RR (1980) Theory of the kinetic isotope effect in proton transfer reactions in a polar medium. J. Chem. Soc., Faraday Trans. 2, 76:1128-1146. https://doi.org/10.1039/F29807601128

Hanggi P, Talkner P, Bercovec M (1990) Reaction rate theory: fifty years after Kramers. Reviews of Modern Physics 62:252-341. doi: 10.1103/RevModPhys.62.251

Kuznetsov AM (1986) A quantum mechanical theory of the proton and electron transfer in weakly polar solvents. J Electroanal Chem 204:97-109. https://doi.org/10.1016/0022-0728(므) $\underline{80511-3}$

Levich VG, German ED, Dogonadze RR et al (1970) Theory of homogeneous involving proton transfer. Electochimica Acta 15: 353-367. https://doi.org/10.1016/0013-4686(70)

Marcus RA (1957) On the theory of oxidation-reduction reactions involving electron transfer. II. Applications to data on the rates of isotopic exchange reactions. J Chem Phys 26:867-871. https://doi.org/10.1063/1.1743423

Marcus RA (1968) Theoretical relations among rate constants, barriers and Broensted slopes of chemical reactions. J Phys Chem 72:891-899. https://doi.org/10.1021/j100849a019

Romanskii IA (2008) Intramolecular reorganization. Deprotonation of toluene with the $\mathrm{CH}_{2} \mathrm{CN}^{-}$anion: An analysis in the framework of gas-phase model. Izvestiya Akad. Nauk. Ser. Khim. 9:1808-1815 [(2008) Russ. Chem. Bull. Int. Ed. 57:1842-1849]_https://doi.org/10.1007/s11172-008-0249-7

Romanskii IA (2018) Study of gas-phase reactions within the modified Marcus model. I.

$\mathrm{CH} 4+\mathrm{CH} 3 \rightarrow \mathrm{CH} 3+\mathrm{CH} 4$. Comp Theor Chem 1125:142-151. https://doi.org/10.1016/j.comptc.2017.12.005

Romanskii IA (2018a) The activated complex position on the reaction coordinate and the problem of curvature - linearity of the Bronsted relation. Comp Theor Chem 1127: 52-

63. https://doi.org/10.1016/j.comptc.2018.01.019

Romanskii IA (2020) Study of gas-phase reactions within the modified Marcus model. III.

$\mathrm{CH} 4+\mathrm{CH} 3 \rightarrow \mathrm{CH} 3+\mathrm{CH} 4.250$ - 2000 K. Comp Theor Chem 1179:112767.

https://doi.org/10.1016/j.comptc.2020.112767

Romanskii IA (2020a) Erratum to "Study of gas-phase reactions within the modified Marcus model. III. CH4+CH3CH3+CH4. 250-2000K". Comput. Theoret. Chem. 1179 (2020) 112769. doi: 10.1016/j.comptc.2021.113382 ISBN: 2210-271X

Szczesniak MM, Scheiner S (1985) Effects of external ions on the dynamics of proton transfer across a hydrogen bond. J Phys Chem 89:1835-1840. https://doi.org/10.1021/j100248a017

\section{Declarations}

The authors declare no competing interests. 


\section{Figures}

\section{Figure 1}

The rate constants over the interval $2000-150 \mathrm{~K}: k$ (curve 1 ), $k_{\mathrm{m}}$ (curve 2).

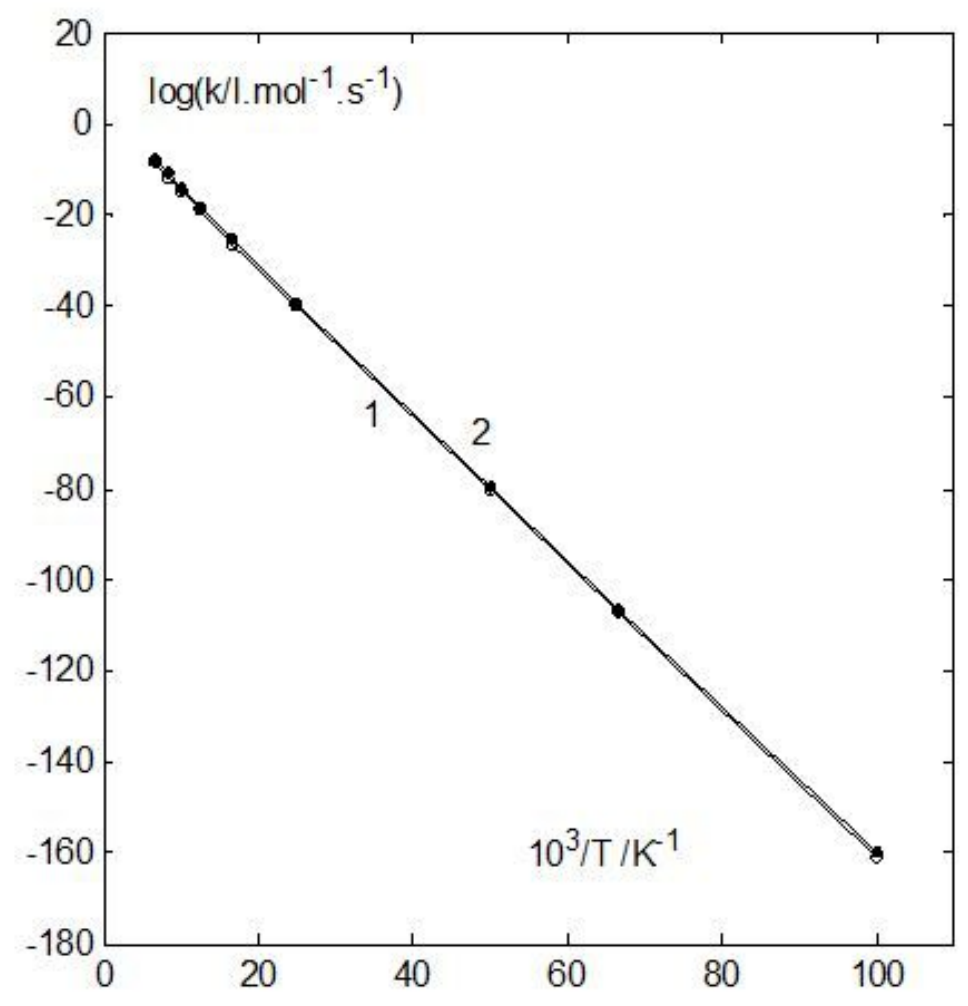

Figure 2

The rate constants over the interval 150 - $10 \mathrm{~K}$; designations - see Fig. 1. 


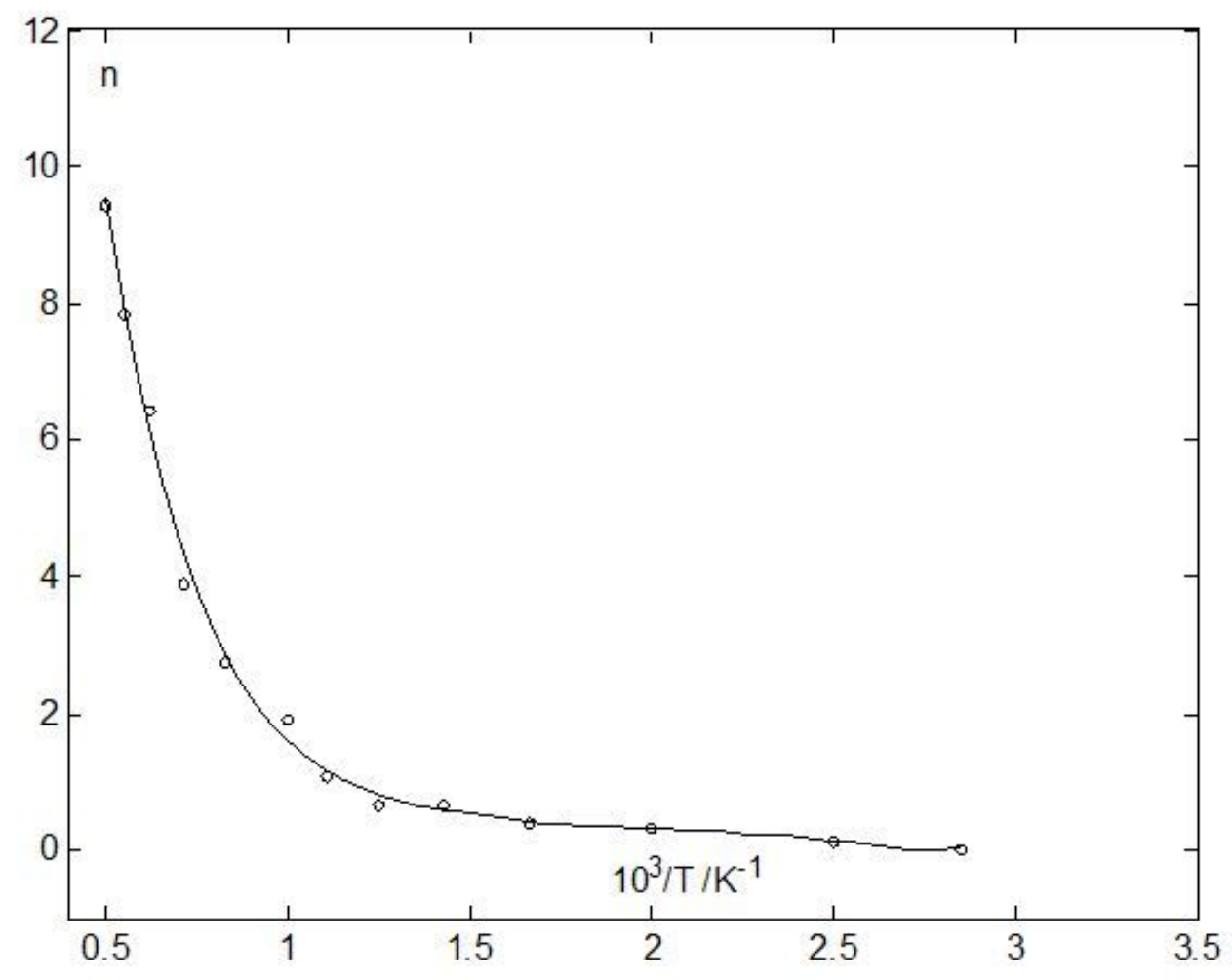

Figure 3

Changes of $\mathrm{n}$ with temperature.

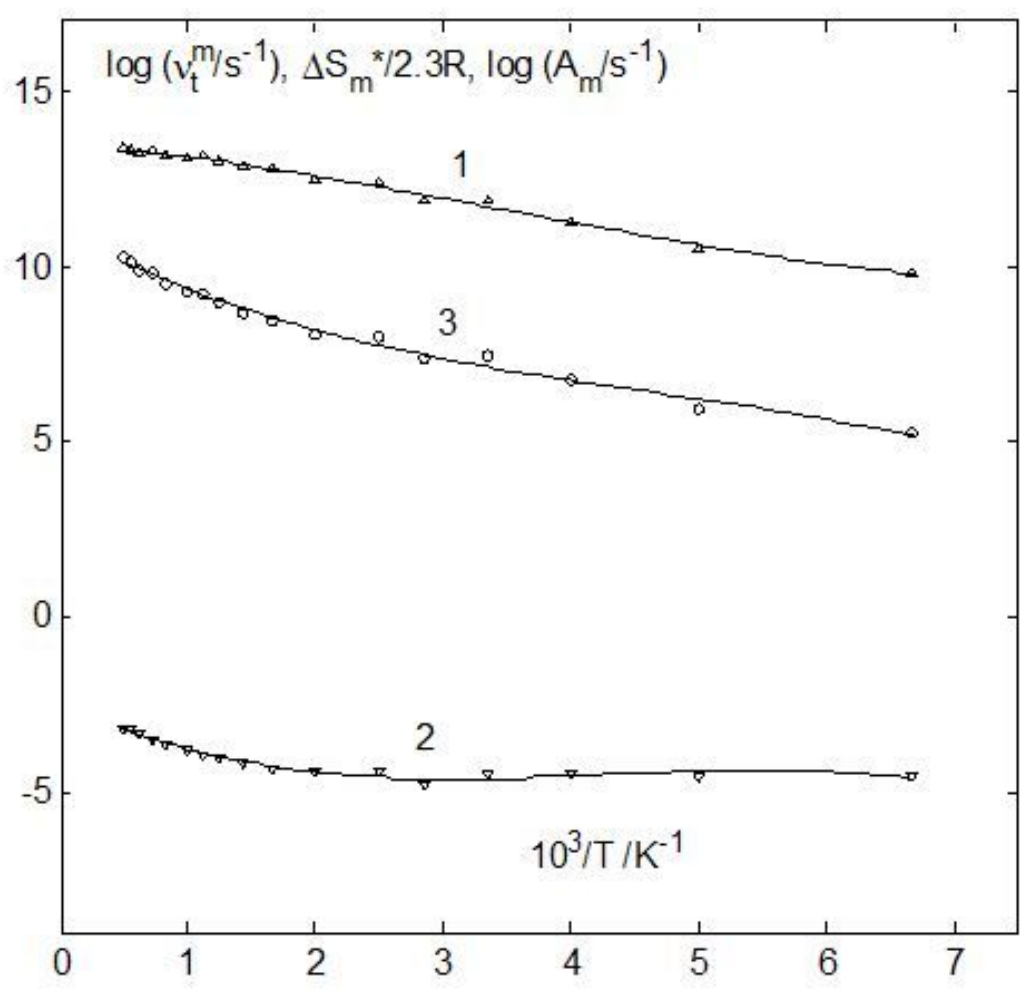

Figure 4 
Changes in terms of Eq. $12 \mathrm{~b}$ with temperature over the interval $2000-150 \mathrm{~K}: \log \mathrm{v}_{\mathrm{t}}^{\mathrm{m}}$ (curve 1), $\Delta S_{m}{ }^{\star} / 2.3 \mathrm{R}$ (curve 2) and log $A_{m}$ (curve 3).

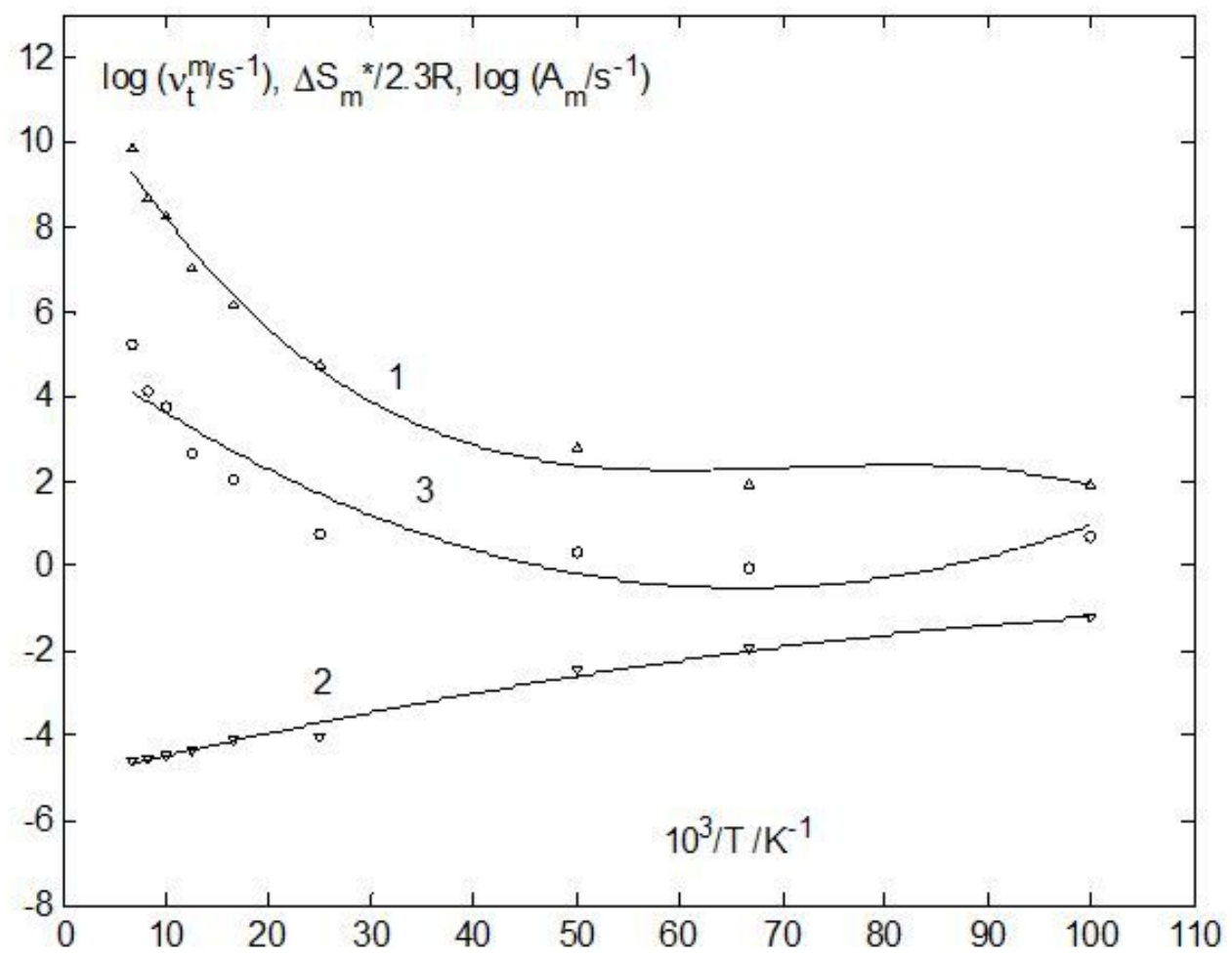

Figure 5

Changes in terms of Eq. 12b with temperature over the interval 150 - $10 \mathrm{~K}$; designations - see Fig. 4.

\section{Figure 6}

Changes in terms of Eq. $12 \mathrm{c}$ with temperature over the interval $2000-150 \mathrm{~K}$ :

$-E_{a}^{\mathrm{m}} / 2.3 R T$ (curve 1), $-\Delta h_{m}{ }^{*} / 2.3 R T$ (curve 2), $-\Delta H_{m}{ }^{*} / 2.3 R T$ (curve 3).

\section{Figure 7}

Changes in terms of Eq. 12c with temperature over the interval $150-10 \mathrm{~K}$; designations - see Fig. 6 .

\section{Figure 8}

Changes in terms of Eq. 12a with temperature over the interval $2000-150 \mathrm{~K}: \log \left(A_{m} / \mathrm{s}^{-1}\right)$ (curve 1), $-\Delta H_{m} * / 2.3 R T$ (curve 2), $\log \left(k_{m} /\right.$ l.mol $\left.{ }^{-1} \cdot \mathrm{s}^{-1}\right)$ (curve 3). Curves 1, 2, and 3 are identical, respectively, to curves: 3 (Fig. 4), 3 (Fig. 6) and 2 (Fig. 1). 


\section{Figure 9}

Changes in terms of Eq. 12a with temperature over the interval $150-10 \mathrm{~K}$; designations - see Fig. 8. Curves 1, 2, and 3 are identical, respectively, to curves: 3 (Fig. 5), 3 (Fig. 7) and 2 (Fig. 2).

\section{Supplementary Files}

This is a list of supplementary files associated with this preprint. Click to download.

- supplementarymaterials.docx 